\section{Regards sur l'économie allemande}

Bulletin économique du CIRAC

$109 \mid 2013$

Varia

\title{
Transfert des savoirs
}

ERLACH Christine, ORIANS Wolfgang, REISACH Ulrike, Wissenstransfer bei Fach- und Führungskräftewechsel - Erfahrungswissen erfassen und weitergeben

\section{(2) OpenEdition}

Édition électronique

URL : http://journals.openedition.org/rea/4577

DOI : $10.4000 /$ rea. 4577

ISSN : 1965-0787

Éditeur

CIRAC

\section{Édition imprimée}

Date de publication : 4 juillet 2013

ISSN : 1156-8992

Référence électronique

"Transfert des savoirs », Regards sur l'économie allemande [En ligne], 109 | juillet 2013, mis en ligne le 19 juillet 2013, consulté le 22 septembre 2020. URL : http://journals.openedition.org/rea/4577 ; DOI : https://doi.org/10.4000/rea.4577

Ce document a été généré automatiquement le 22 septembre 2020.

(c) CIRAC 


\section{Transfert des savoirs}

ERLACH Christine, ORIANS Wolfgang, REISACH Ulrike, Wissenstransfer bei Fach- und Führungskräftewechsel - Erfahrungswissen erfassen und weitergeben

\section{RÉFÉRENCE}

ERLACH Christine, ORIANS Wolfgang, REISACH Ulrike, Wissenstransfer bei Fach- und Führungskräftewechsel - Erfahrungswissen erfassen und weitergeben, Hanser Verlag, Munich, 2013, 284 p.

Ce manuel apporte des solutions pour une meilleure transmission au sein des entreprises du savoir, du savoir-faire et des techniques face aux défis actuels (déclin démographique). Par étapes successives, les auteurs exposent les modèles organisationnels et les méthodes de management qui permettent d'optimiser le transfert de compétences. Des cas concrets simples et des interviews d'experts viennent éclairer les propos des auteurs pour la mise en pratique de ces conseils. (rm) 